\title{
A Role for Forkhead Box A1 in Acute Lung Injury
}

\author{
Lan Song, ${ }^{1,2}$ Bin Zhang, ${ }^{1}$ Yansheng Feng, ${ }^{1}$ Xinjing Luo, ${ }^{1}$ Xing Wei, ${ }^{1}$ and Xianzhong Xiao ${ }^{1,3}$
}

\begin{abstract}
Forkhead box protein A1 (FoxA1) is an evolutionarily conserved winged helix transcription factor with diverse regulatory functions. However, little is known about the role of FoxA1 in acute lung injury (ALI) and pulmonary cell injury. In this study, an in vivo model was employed whereby rats were administered an intravenous injection of oleic acid (OA, $0.1 \mathrm{ml} / \mathrm{kg})$, and alveolar type II epithelial cells (AT-2 cells) injury was induced by hydrogen peroxide $\left(\mathrm{H}_{2} \mathrm{O}_{2}\right)$ in vitro. OA injection resulted in lung injury and AT-2 cells apoptosis in vivo. OA injection and $\mathrm{H}_{2} \mathrm{O}_{2}$ upregulated FoxA1 mRNA and protein in lung tissue of the in vivo ALI model and in $\mathrm{H}_{2} \mathrm{O}_{2}$ challenged AT-2 cells. Overexpression of FoxA1 promoted apoptosis, whereas FoxA1 deficiency, induced by antisense oligonucleotides, decreased AT-2 cells apoptosis induced by $\mathrm{H}_{2} \mathrm{O}_{2}$, as shown by flow cytometry. These results suggest that FoxA1 may play an important role in ALI by promoting apoptosis of pulmonary epithelial cells.
\end{abstract}

KEY WORDS: acute lung injury; forkhead box A1; apoptosis.

\section{INTRODUCTION}

Acute lung injury (ALI) or acute respiratory distress syndrome (ARDS) is a severe complication and a significant cause of mortality in critically ill patients [1-4]. Despite decades of research, few therapeutic strategies for clinical ALI/ARDS have emerged, and the current specific treatment options remain limited [5-9]. ALI/ARDS continues to be an important contributor to prolonged mechanical ventilation in the intensive care unit, and ALI/ARDS-associated mortality remains high at $30-50 \%$ despite optimal supportive care $[4,6,7,9]$.

\footnotetext{
${ }^{1}$ Laboratory of Shock, Department of Pathophysiology, Xiangya School of Medicine, Central South University, 110 Xiangya Road, Changsha, Hunan 410078, People's Republic of China

${ }^{2}$ Nanhua University, College of Life Science, Department of Biochemistry and Molecular Biology, Hengyang, Hunan 421001, People's Republic of China

${ }^{3}$ To whom correspondence should be addressed at Laboratory of Shock, Department of Pathophysiology, Xiangya School of Medicine, Central South University, 110 Xiangya Road, Changsha, Hunan 410078, People's Republic of China. E-mail: xianzhongxiao@xysm. net
}

Intravenous injection of pure oleic acid (OA) has been demonstrated to cause respiratory distress in several different animal species. The precise mechanism by which OA promotes lung injury is not clear but appears to involve the production of reactive oxygen species leading to endothelial and epithelial cell damage [10-12].

Many studies suggest that the epithelial injury that occurs during ALI/ARDS may be attributed to apoptosis of alveolar epithelial cells in response to soluble mediators such as Fas ligand, and that blockade of such mediators may be beneficial in preventing or treating ALI/ARDS [13, 14].

Forkhead box A1 (FoxA1; previously termed hepatocyte nuclear factor (HNF)-3 $\alpha$ ) is a member of the winged helix family of transcription factors and shares structural similarities with FoxA2 and FoxA3 (previously termed HNF-3 $\beta$, and $\gamma$, respectively). Foxa genes are widely expressed during embryonic development in vertebrates. During formation of the definitive endoderm, FoxA1 is detected in the notochord and floor plate [15-18]. Later in embryonic development and in adulthood, FoxA1 is detected in tissues of endodermal, ectodermal, and mesodermal origin [19-21]. In the lung, 
FoxA1 and FoxA2 are first expressed at the onset of lung bud formation and expression persists in the adult lung, where FoxA1 and FoxA2 are coexpressed in epithelial cells in conducting airways and in alveolar type II epithelial cells (AT-2 cells) [19]. Although FoxA1 is not required for respiration at birth, deletion of FoxA1 influences lung morphogenesis and epithelial cell differentiation at distinct times during perinatal development. Before birth, FoxAl deletion in the mouse lung delayed maturation of AT-2 cells and bronchiolar Clara cells. Immunostaining for surfactant protein (SP)-B and SP-C was positive but reduced in the Foxal-/- mice before birth, whereas Clara cell secretory protein (CCSP) mRNA and protein expression was markedly delayed in the Foxal-/- mice [22]. Despite stage-specific decreases in SP-B and SP-C, Foxal-/- mice survived at birth [22]. The delay in maturation before birth due to FoxA1 deletion could render Foxal-deficient mice susceptible to respiratory distress at earlier gestations [22]. Recently it has been reported that FoxAl can attenuate NKX2.1-dependent transcription of surfactant protein A (SP-A), and that SP-A is an inhibitor of apoptosis in AT-2 cells in vivo [23-25]. Given the role of FoxA1 in lung maturation and in attenuation of SP-A transcription, we hypothesized that FoxAl may be involved in the pathophysiology of ALI.

In the present study, expression of FoxA1 during ALI was investigated in a rat model of ALI and in the AT- 2 cells. In addition, the role of FoxA1 in apoptosis of AT-2 cells was investigated.

\section{MATERIAL AND METHODS}

\section{Animals}

All animal procedures were performed according to the Helsinki declaration and approved in advance by the Animal Care and Use Committee of Central South University, Changsha China. Sprague-Dawley rats $(156 \pm 13.8 \mathrm{~g})$ were purchased from the Experimental Animal Center of Central South University and allowed to acclimate for 3 days before experimentation. Animals were fed rodent chow and water ad libitum.

\section{ALI Model}

Rats were randomly divided into eight groups. ALI was induced by injection of OA $(0.1 \mathrm{~mL} / \mathrm{kg}$; Sigma, St. Louis, Mo) into the caudal vein for a 1-min period. Rats were anesthetized by intraperitoneal injection of $10 \%$ chloral hydrate (QingDao YuLong Algae CO. LTD., QingDao, China) and kept in the supine position while spontaneous breathing was monitored. Rats were sacrificed at $0,0.5,1,2,4,8,16,24 \mathrm{~h}$ after injury, and those sacrificed at $0 \mathrm{~h}$ were used as controls. After the experimental protocol was completed, lung tissue from all animals ( $n=3$ per time point) was rapidly obtained from the right upper lobe and desiccated in an oven at $60^{\circ} \mathrm{C}$ for $72 \mathrm{~h}$ so that the lung wet/dry weight ratio could be measured. ALI induction was verified by pathological examination of the lung.

\section{Lung Histopathology}

At necropsy ( $n=3$ per time point), the left lung was excised and fixed with $4 \%$ paraformaldehyde. After $24 \mathrm{~h}$ the lung tissue was dehydrated with graded alcohol and embedded in paraffin at $52^{\circ} \mathrm{C}$. Sections were prepared and stained with hematoxylin and eosin for evaluation of the severity of lung injury. Each lung section was blindly assigned a lung injury score (LIS) by two pathologists using the method described by Nishina et al. [26]. Briefly, lung tissue sections were assessed for alveolar congestion, hemorrhage, infiltration or aggregation of neutrophils in the airspace or vessel wall, and thickness of the alveolar wall/hyaline membrane. The degree of lung injury was scored as follows: 0 , minimum; 1 , mild; 2, moderate; 3, severe; and 4, maximum damage. For each animal, six high-magnification fields were randomly selected for grading and an average LIS score was calculated.

\section{Caspase-3 Activity Assay}

Caspase- 3 activity was determined using a caspase3 activity kit (Beyotime Institute of Biotechnology, Haimen, China). At $0,0.5,1,2,4,8,16,24 \mathrm{~h}$ after OA administration ( $n=3$ per time point), rats were sacrificed. Lung tissue from all animals $(n=3$ per time point) was rapidly obtained from the right lower lobe was collected, rinsed with cold phosphate-buffered saline (PBS), and homogenized on ice in lysis buffer $(3-10 \mathrm{mg} / 100 \mu \mathrm{l})$. Homogenates was transferred to $1.5 \mathrm{ml}$ centrifuge tubes, lysed on ice for $5 \mathrm{~min}$ and centrifuged at $18,000 \mathrm{~g}$ for $10 \mathrm{~min}$ at $4^{\circ} \mathrm{C}$. Caspase-3 activity assays were performed in 96-well microtitre plates by incubation of $10 \mu \mathrm{l}$ tissue lysate protein in $80 \mu \mathrm{l}$ reaction buffer (1\% NP-40, $20 \mathrm{mM}$ Tris- $\mathrm{HCl}$ (pH 7.5), $137 \mathrm{mM} \mathrm{Nad}$ and $10 \%$ glycerol) containing $10 \mu \mathrm{l}$ caspase-3 substrate (Ac-DEVD-pNA) $(2 \mathrm{mM})$ at $37^{\circ} \mathrm{C}$ for $4 \mathrm{~h}$. Samples were measured with an ELISA 
reader at an absorbance of $405 \mathrm{~nm}$. Caspase-3 activities were expressed as the percentage of enzyme activity compared to control. All experiments were carried out in triplicate.

\section{Assessment of AT-2 Cells Apoptosis in Lung Tissue of ALI}

The TUNEL method was used to identify apoptotic cells in dewaxed paraffin sections (ApopTag peroxidase in situ apoptosis detection S7100-kit; Oncor-Appligene, Heidelberg, Germany) according to the manufacturers recommendations. In short, paraffin-embedded sections were deparaffinized, pretreated with proteinase $\mathrm{K}$, and rinsed and quenched in $3 \% \mathrm{H}_{2} \mathrm{O}_{2}$. Samples were next incubated with terminal deoxynucleotidyl transferase (TdT), in the presence of biotinylated nucleotides. The slides were then washed with stop-wash buffer, incubated with streptavidin labeled horseradish peroxidase (HRP) and rinsed and stained with diaminobenzidine (DAB). As a control, consecutive sections were treated identically only with $\mathrm{TdT}$ being omitted in the primary incubation step.

\section{TUNEL/anti-MNF116 Double Staining}

The TUNEL method was used as described above. Subsequently, sections were additionally stained with the monoclonal anticytokeratin antibody MNF116 (Dako, Carpinteria, Calif., USA), which is an established marker of AT-2 cells [27]. Sections were blocked using $0.1 \%$ bovine serum albumin in Tris buffered saline (TBS; Sigma-Aldrich), followed by incubation with the MNF-116 antibody (monoclonal mouse anti-human cytokeratin clone MNF-116; DakoCytomation, Hamburg, Germany; 1:150 dilution in TBS). Antigen detection was performed by using an alkaline phosphatase color development kit (Dingguo, Beijing, China), according to the manufacturers recommendations. For staining of nuclei, nuclear fast red (Dingguo, Beijing, China) was used.

\section{Preparation of AT-2 Epithelial Cells}

Alveolar type 2 cells were isolated as described previously [44, 45]. In brief, untreated animals were killed by exsanguination via the descending aorta in a deep intraperitoneal anesthesia as described above. Lungs were perfused with PBS via the right ventricle. To reduce AMs in the lung, the trachea was cannulated and was repeatedly flushed with PBS (eight times,
$10 \mathrm{~mL}$ ). Next, the lungs were placed for $20 \mathrm{~min}$ in a water bath $\left(37^{\circ} \mathrm{C}\right)$. Forty milliliters of PBS containing $172 \mathrm{U}$ of elastase (Worthington Biochemical, Freehold, $\mathrm{NJ}$ ), was slowly infused into the airways via the intratracheal catheter. The heart and remaining connective tissue were then removed, and the lungs were minced with scissors after adding 1,000 U of DNAse I (Sigma). Enzyme activity was blocked by adding $5 \mathrm{~mL}$ of ultralow IgG FCS (Life Technologies, Rockville, Md). The cell suspension was then incubated at room temperature, gently stirred for $20 \mathrm{~min}$, and filtered successively through polyester meshes of 500-, 200-, and $105-\mu \mathrm{m}$ pore diameter (VWR International, Darmstadt, Germany) and afterward suspended in $30 \mathrm{~mL}$ DMEM (Life Technologies). The cells were centrifuged at $450 \mathrm{~g}$ for $10 \mathrm{~min}$ and then resuspended in $45 \mathrm{~mL}$ of DMEM. Next, the cells were plated in 100-mm Petri dishes precoated with rat $\mathrm{IgG}(302 \mathrm{~g} / \mathrm{mL}$; Sigma) and incubated for $1 \mathrm{~h}$ at $37^{\circ} \mathrm{C}$ to remove remaining AMs. AT-2 cells were then carefully collected by rinsing the Petri dishes with DMEM three times. After centrifugation, the cell pellet was carefully resuspended in 10 to $20 \mathrm{~mL}$ DMEM containing $1 \%$ penicillin, $1 \%$ streptomycin, $1 \%$ L-glutamine $(200 \mathrm{mM})$, and $1 \%$ nonessential amino acids $(10 \mathrm{mM})$ (all from Life Technologies, Grand Island, NY), in the presence of $10 \%$ heatinactivated FBS. Cells were counted, and viability was tested by trypan blue and found to be greater than $95 \%$. Finally, cells were plated on eight-well chamber slides (Lab-Tek II, with cover RS glass slides, Nalge Nunc Int, Naperville, Ill) at a cell count of $1 \times 10^{6} / \mathrm{mL}(0.5 \mathrm{~mL}$ per well). Cells were washed after $48 \mathrm{~h}$ of culture in an incubator at $37^{\circ} \mathrm{C}$ at a $5 \% \mathrm{CO}_{2}$ atmosphere to remove nonadherent cells. After further incubating cells with DMEM containing $0.5 \%$ FBS, $2 \%$ nonessential amino acids, $2 \%$ penicillin/streptomycin, and 2\% L-glutamine for $18 \mathrm{~h}$, AT- 2 cells were used for experiments.

\section{Cell Culture and Induction of Acute Cell Injury}

For the incubation experiments, AT-2 cells from untreated male Sprague-Dawley-rats were cultured for $66 \mathrm{~h}$ as described above. Since reactive oxygen species are the main mediators of OA-induced ALI, we used $\mathrm{H}_{2} \mathrm{O}_{2}$ to simulate the pulmonary epithelial cell injury that occurs in ALI. AT-2 cells were stimulated with hydrogen peroxide $\left(\mathrm{H}_{2} \mathrm{O}_{2}, 0.5 \mathrm{mM}\right.$, Xilong Chemical Factory, China). A dose of $\mathrm{H}_{2} \mathrm{O}_{2}$ was chosen that was consistent with previous reports $[28,29]$ and with our pilot study, in which we found that a lower dose 
(0.25 mM) of $\mathrm{H}_{2} \mathrm{O}_{2}$ did not induce obvious AT-2 cells injury. At $0,1,2,4,8,16,24 \mathrm{~h}$ after treatment, cells were harvested and mRNA and protein was extracted to determine FoxA1 expression. Cells harvested at $0 \mathrm{~h}$ were used as control.

\section{RNA Extraction, and Reverse Transcription- Polymerase Chain Reaction}

Total RNA from frozen lung tissue and AT-2 cells was extracted with TRIzol reagent (Invitrogen) according to the manufacturers instructions. $1 \mu \mathrm{g}$ of total RNA was reverse transcribed using a reverse transcription kit (Fermentas) and PCR was performed using the Biometra iCycler (Biometra). For PCR amplification, the following primers were used: GAPDH, 5'-AAG CCC ATC ACC ATC TTC CA-3' (Forward) and 5'-CCT GCT TCA CCA CCT TCT TG-3' (Reverse); FoxA1, 5'-AGC TGC ATG TCC TTG GTT CT-3' (Forward) and 5'-TGC CTG AAG CTT GTG ACA TC-3' (Reverse).

\section{Western Blot Analysis}

Protein lysates from frozen lung tissue and AT-2 cells were resolved on $12 \%$ SDS-PAGE gels and then transferred to PVDF membranes (Schleicher \& Schuell). Membranes were blocked overnight in PBS containing $10 \%$ nonfat dry milk with $0.5 \%$ Tween-20, and incubated with primary antibodies for $2 \mathrm{~h}$. HRPconjugated anti-rabbit or anti-mouse $\operatorname{IgG}$ was used as the secondary antibody. Immunoreactive bands were visualized using DAB (Boster Biological Technology, China). Anti-glyceraldehyde-3-phosphate dehydrogenase (GAPDH) was used to normalize for equal amounts of proteins and to calculate the relative induction ratio. The following antibodies were used: Rabbit anti-FoxA1 polyclonal antibody (Abcam, UA); mouse anti-GAPDH) monoclonal antibody (Sigma); HRP-conjugated antimouse and anti-rabbit IgG (Boster Biological Technology, China).

\section{Generation of Constructs}

Oligonucleotide primers were designed to amplify the coding sequence of rat FoxA1 yielding a $1.4 \mathrm{~kb}$ product. The oligonucleotide primers are as follows: FoxA1, 5'-CCG GAA TTC AGG GTG GCT CCA GGA TGT TAG-3' (Forward) and 5'-CCC AAG CTT GAA GTG TTT AGG ACG GGT ATG-3' (Reverse). The PCR product was electrophoresed on a $0.9 \%$ agarose gel and the $1.4 \mathrm{~kb}$ fragment was purified with a Qiagen purification system (Qiagen). The resulting fragment was inserted into the pcDNA3.1(-) vector (Stratagene) and sequenced commercially (Invitrogen).

\section{Lipofectamine-Mediated Gene Transient Transfection}

Transient transfection of AT-2 cells was performed according the manufacturers instructions using lipofectamine $2000^{\mathrm{TM}}$ (Invitrogen). Briefly, approximately $5 \times$ $10^{5}$ cells were seeded to flasks containing $5 \mathrm{~mL}$ of appropriate complete growth medium and incubated at $37^{\circ} \mathrm{C}$ with $5 \% \mathrm{CO}_{2}$ until the cells were $70 \%$ to $80 \%$ confluent $(24 \mathrm{~h})$. After rinsing with serum-free, antibiotic-free medium, cells were transfected with either $10 \mu \mathrm{g}$ pcDNA3.1-FoxA1 in $20 \mu \mathrm{L}$ lipofectamine (experimental group) or $10 \mu \mathrm{g}$ pcDNA3.1 in $20 \mu \mathrm{L}$ lipofectamine (vector control), followed by incubation at $37^{\circ} \mathrm{C}$ in a $\mathrm{CO}_{2}$ incubator for $6 \mathrm{~h}$. Medium was replaced with complete medium supplemented with $10 \%$ fetal bovine serum, and cells were treated with $0.5 \mathrm{mM} \mathrm{H}_{2} \mathrm{O}_{2}$ for $24 \mathrm{~h}$ to induce apoptosis.

\section{Loss-of-Function Assay with Morpholino Oligonucleotides}

A FoxA1 morpholino antisense oligonucleotide was designed to target the site of FoxA1 translation initiation (FoxA1-AS, tcttcacagttcctaacat) and was synthesized commercially (Invitrogen). $24 \mathrm{~h}$ after plating, morpholinos were transfected into AT-2 cells using lipofectamine $2000^{\mathrm{TM}}$ according to the manufacturer's instructions (Invitrogen). The specificity of the antisense oligonucleotide was validated by employing a control oligonucleotide (FoxA1-Ctrl, gcggagccaggtctagctt) and a lipofectamine only treated sample (Lipo). Cells were treated with $0.5 \mathrm{mM} \mathrm{H}_{2} \mathrm{O}_{2}$ for $24 \mathrm{~h}$ to induce apoptosis.

\section{Analysis of Apoptosis by Flow Cytometry}

The apoptosis rate was measured using flow cytometry. Briefly, AT-2 cells were washed with PBS $(\mathrm{pH} 7.4)$, fixed in cold $70 \%(v / v)$ ethanol, and incubated at $-20^{\circ} \mathrm{C}$ for at least $2 \mathrm{~h}$. The fixed cells were harvested by centrifugation at $250 \mathrm{~g}$ for $5 \mathrm{~min}$. Cell pellets were resuspended in $1 \mathrm{ml}$ of PBS at room temperature for $10 \mathrm{~min}$, centrifuged and resuspended in $500 \mu \mathrm{l}$ of PBS containing $0.2 \mathrm{~g} / \mathrm{L}$ RNase $\mathrm{A}$, and incubated at $37^{\circ} \mathrm{C}$ for $30 \mathrm{~min}$. After incubation, the cells were stained with $20 \mathrm{~g} / \mathrm{L}$ propidium iodide at $4^{\circ} \mathrm{C}$ for $30 \mathrm{~min}$. Cellular fluorescence was measured using a FACSCalibur flowcytometer (BD BioSciences, San Jose, CA, USA). The 
Table 1. Comparison of Severity of Alveolar Inflammation and Lung Wet/dry Weight at Different Time Points after OA Injection

\begin{tabular}{lccccccccc}
\hline & \multicolumn{1}{c}{$0 \mathrm{~h}$} & $0.5 \mathrm{~h}$ & $1 \mathrm{~h}$ & $2 \mathrm{~h}$ & $4 \mathrm{~h}$ & $8 \mathrm{~h}$ & $16 \mathrm{~h}$ & $24 \mathrm{~h}$ \\
\hline Number of rats & 3 & 3 & 3 & 3 & 3 & 3 & 3 & 3 \\
Lung injury score & $0.92 \pm 0.036$ & $1.55 \pm 0.086$ & $2.0 \pm 0.1^{*}$ & $2.22 \pm 0.12^{*}$ & $2.33 \pm 0.07^{*}$ & $2.46 \pm 0.05^{*}$ & $2.56 \pm 0.055^{*}$ & $2.62 \pm 0.035^{*}$ \\
Lung wet/dry weight & $3.6 \pm 0.14$ & $10 \pm 0.53^{*}$ & $10.7 \pm 0.31^{*}$ & $9.8 \pm 0.26^{*}$ & $10 \pm 0.40^{*}$ & $9.3 \pm 0.27^{*}$ & $7.8 \pm 0.32^{*}$ & $5.8 \pm 0.18^{*}$ \\
\hline
\end{tabular}

All values are expressed as mean \pm SD from three animals per group per time point

*Statistically significant versus the control group, $P<0.05$

relative DNA content indicated the cell cycle distribution of a population of cells. Apoptotic cells resulted in the appearance of a subdiploid peak in the cell cycle profile. The percentage of apoptotic cells was determined using BD CellQuest software (BD BioSciences).

\section{Statistical Analysis}

The statistical software SPSS version 11.5 was used for data analyses. All data were expressed as the mean \pm SD. Continuous parametric data were subjected to analysis of variance followed by the Student-Newman-Keuls post hoc test for determining differences between groups. A Nemenyi test was used to detect any lung injury score differences between groups. A chisquare test was used to determine statistical differences in the rate of apoptosis. A $p$ value $<0.05$ was considered statistically significant.

\section{RESULTS}

\section{Assessment of Degree of Lung Injury in OA-induced ALI}

Lung wet/dry weight ratio was significantly increased at $0.5-24 \mathrm{~h}$ following $\mathrm{OA}$ injection and maximum lung wet/dry weight ratio occurred at $1 \mathrm{~h}$ (Table 1). Histological examination by light microscopy revealed that in control lung, alveoli were fully distended and no alveolar wall edema or congestion was found. Occasional inflammatory cells were scattered throughout the lung. In contrast, all typical features of OA-induced lung injury were observed in the lung tissue from OAtreated animals as early as $1 \mathrm{~h}$ after treatment. Features observed that were consistent with ALI included: alveolar hemorrhage, destruction of alveolar attachment points, an increased number of interstitial cells and extensive neutrophil infiltration (Fig. 1), which were most pronounced $24 \mathrm{~h}$ after OA challenge. The LIS was significantly increased in the OA group (Table 1). These results demonstrated that the induction of ALI in rat using OA was successful.

\section{Apoptosis of AT-2 Cells in Lung Tissue of Rats Displaying ALI}

Since caspase-3 has been shown to play a pivotal role in the execution phase of apoptosis [30], we examined caspase- 3 activity in lung tissue. As shown in Fig. 2a, following administration of OA, lung tissue displayed a significant increase in caspase-3 activity from $4 \mathrm{~h}$, and maximal caspase-3 activity was observed $16 \mathrm{~h}$ after OA treatment.

Double immunostaining for TUNEL and the specific AT-2 cells marker MNF116 [27] revealed that AT-2

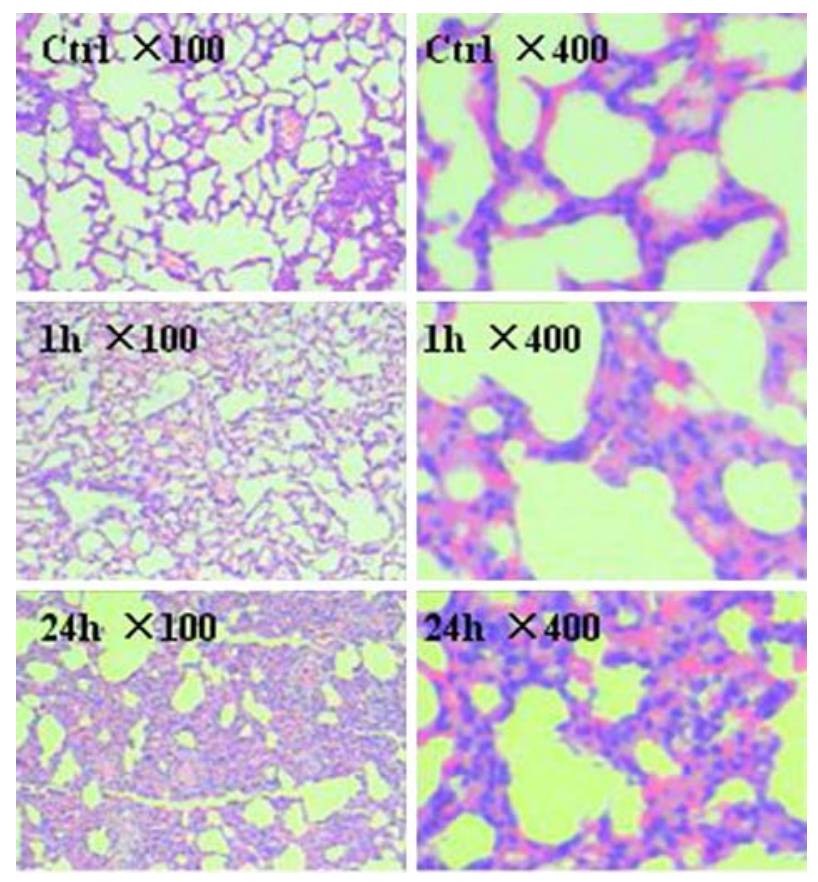

Fig. 1. Histologic changes during ALI induced by oleic acid. Hematoxylin and eosin staining of lung tissue from a rat ALI model induced by oleic acid $(0.1 \mathrm{ml} / \mathrm{kg}$, i.v.). 
Fig. 2. Apoptosis of pulmonary epithelial cells in rat lung tissue of ALI induced by oleic acid. a Caspase-3 activation in lung tissue treated with oleic acid $(0.1 \mathrm{ml} / \mathrm{kg}$, i.v. $)$. Caspase-3 activities at different time points were determined using a caspase- 3 activity kit. Values were expressed as the ratio of caspase- 3 activation levels to control levels, and the value of control was set to 1 . The relative values of all samples were determined and expressed as means \pm SD for three experiments carried out in duplicate. *, Statistically significant versus control group $P<0.05$. b Co-staining for TUNEL activity (brown), and MNF116 (blue) which stains alveolar epithelial type II cells. I, control rat lung demonstrating no apoptosis in alveolar cells $(\times 400)$; II rat lung $24 \mathrm{~h}$ after OA injection demonstrates apoptosis in alveolar type II epithelial cells. $\longrightarrow$ apoptosis cell with MNF-116 positive signals, $\rightarrow$ MNF116 positive signals without apoptosis; $\cdots \cdots$ apoptosis cells without MNF-116 positive signals.

cells apoptosis was induced at $4 \mathrm{~h}$ following OA injection, and reached a maximum at $24 \mathrm{~h}$ (Fig. 2b).

\section{Expression of FoxA1 in Lung Tissue of Rats Displaying ALI}

As shown in Fig. 3a and b, OA treatment led to a sustained increase in FoxA1 mRNA levels from 0.5 to $24 \mathrm{~h}$ and FoxA1 protein levels from 2 to $24 \mathrm{~h}$. Maximal expression levels of FoxA1 mRNA and protein were observed at $8 \mathrm{~h}$ or $24 \mathrm{~h}$, respectively.

\section{Evaluation of FoxA1 Expression and Apoptosis following $\mathrm{H}_{2} \mathrm{O}_{2}$-mediated Injury of the AT-2 Cells}

Following treatment of AT-2 cells with $\mathrm{H}_{2} \mathrm{O}_{2}$ (0.5 mM), FoxA1 mRNA and protein were increased at $1 \mathrm{~h}$ and $2 \mathrm{~h}$. Interestingly, maximum expression of FoxA1 mRNA and protein were also found at $8 \mathrm{~h}$ and 24 h. (Fig. 4). Additionally, flow cytometry data demonstrated that apoptosis was significantly increased at 16 and $24 \mathrm{~h}$ in response to $\mathrm{H}_{2} \mathrm{O}_{2}(0.5 \mathrm{mM})$ (Fig. 5).

\section{Role of FoxA1 in $\mathrm{H}_{2} \mathrm{O}_{2}$-mediated Apoptosis of AT-2 Cells}

In order to determine the role of FoxA1 in $\mathrm{H}_{2} \mathrm{O}_{2}$ mediated apoptosis of AT-2 cells, cells were transfected with FoxA1 antisense oligonucleotides. Successful inhibition of basal FoxA1 expression was assessed by RT-PCR and Western blot (Fig. 6a). Following antisense-mediated inhibition of basal FoxA1 expression, $\mathrm{H}_{2} \mathrm{O}_{2}(0.5 \mathrm{mM})$-mediated apoptosis was significantly decreased compared to control groups at $24 \mathrm{~h}$ (Fig. 6b). The effect of FoxA1 overexpression on apoptosis of AT2 cells was also assessed. As shown in Fig. 6c and d,
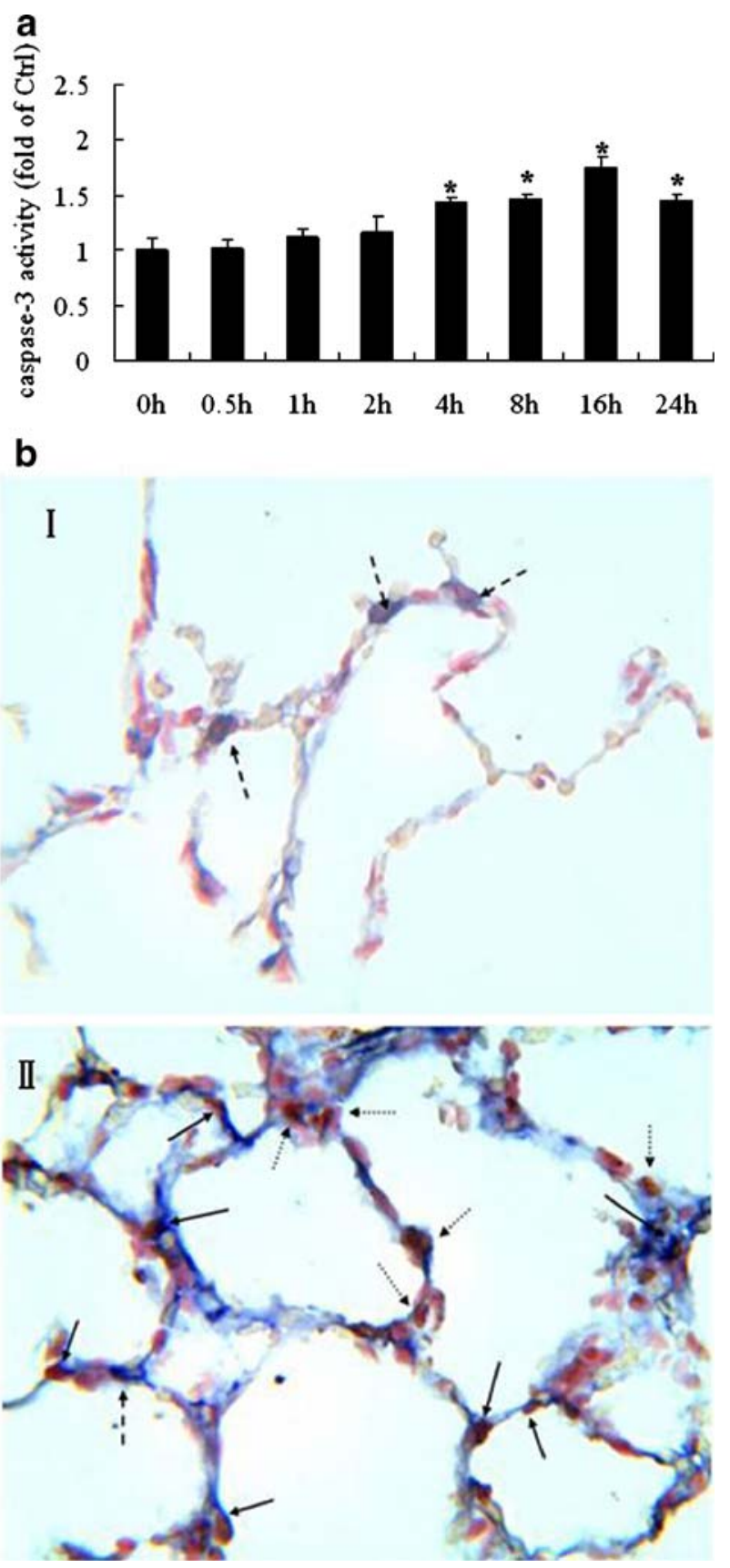

over-expression of FoxA1 increased the rate of $\mathrm{H}_{2} \mathrm{O}_{2}$ mediated apoptosis in AT-2 cells at $24 \mathrm{~h}$.

\section{DISCUSSION}

ALI/ARDS usually occurs during the late stages of many severe illnesses, and the mortality rate remains 
a
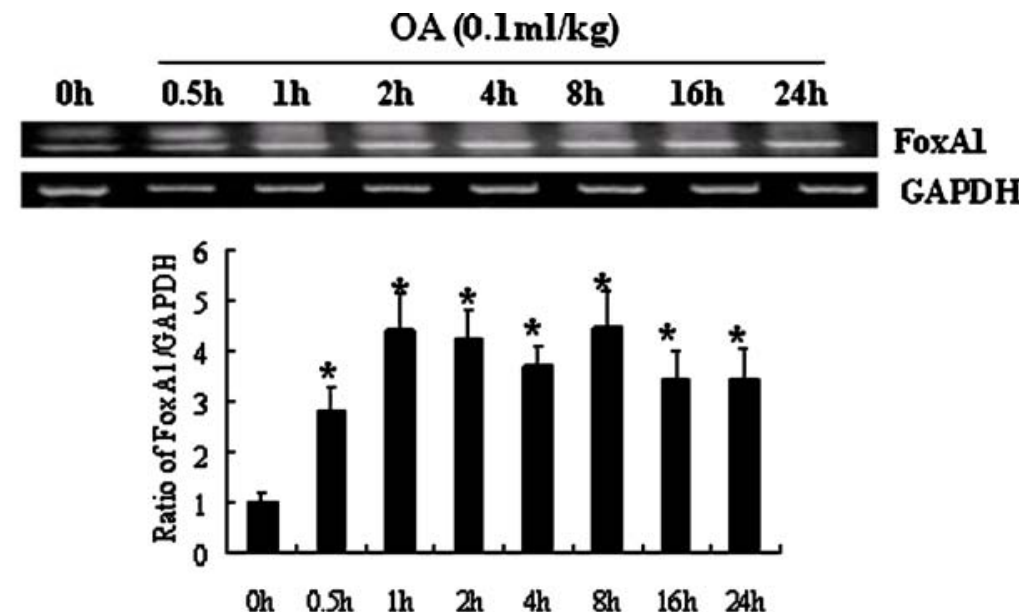

b

OA $(0.1 \mathrm{ml} / \mathrm{kg})$
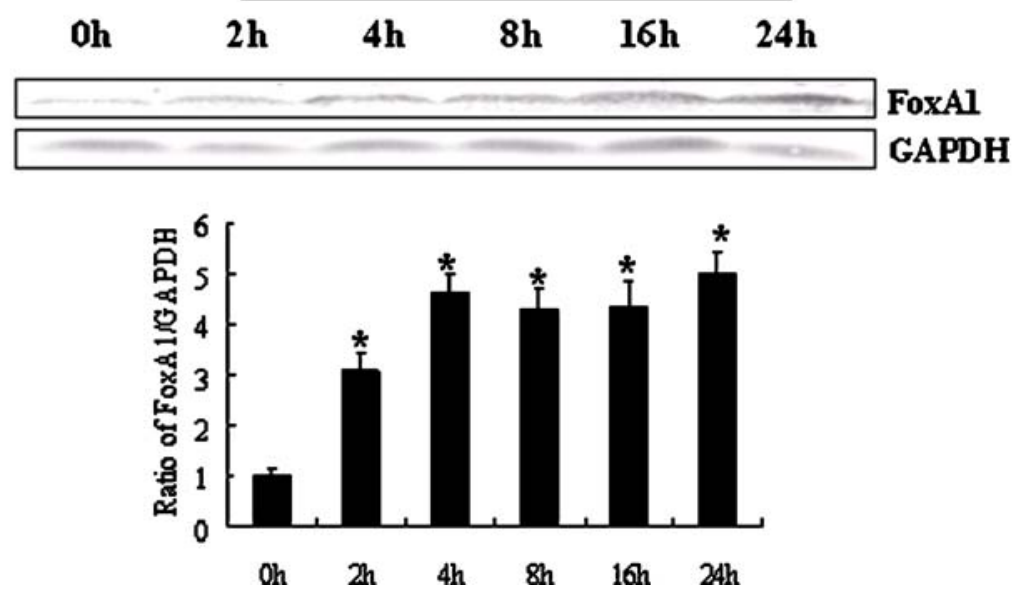

Fig. 3. Expression of FoxA1 in lung tissue of ALI. a mRNA levels of FoxA1 were determined by RT-PCR in lung tissues of an ALI model induced by oleic acid $(0.1 \mathrm{ml} / \mathrm{kg}$, i.v.). b Protein levels of FoxA1 at different time points were determined by Western blot in lung tissues of ALI induced by oleic acid $(0.1 \mathrm{ml} / \mathrm{kg}$, i.v.). The results were expressed as means $\pm \mathrm{SD}$ of three experiments in duplicate. *Statistically significant versus control group, $P<0.05$.

high. Some advances in ALI/ARDS treatment including preventive low-volume ventilation, administration of activated protein $\mathrm{C}$, and administration of high doses of steroids alone or in combination with immunosuppressants have been considered to have beneficial effects and are prescribed for ALI/ARDS patients [7, 31]. However, clinical trials have failed to show improved survival of patients at either late or early stages of ARDS.

The role of cellular apoptosis in ALI is complex. Two main hypotheses linking apoptosis with the pathogenesis of ALI have been postulated, namely the "neutrophil hypothesis" and the "epithelial hypothesis".
The neutrophil hypothesis suggests that neutrophil apoptosis plays an important role in the resolution of inflammation, and predicts that inhibition of neutrophil apoptosis or inhibition of apoptotic neutrophil clearance is deleterious in ALI $[32,33]$. The epithelial hypothesis suggests that the epithelial injury that occurs during ALI is associated with apoptotic death of alveolar epithelial cells and predicts that anti-apoptotic therapeutic agents may be beneficial in preventing or treating ALI [13, 34, 35]. Our results showed that caspase- 3 activity was increased in lung tissue following challenge with OA. In addition, co-staining for TUNEL and anti-MNF116 demonstrated that OA injection induces apoptosis of 
a $\mathrm{H}_{2} \mathrm{O}_{2}(0.5 \mathrm{mM})$
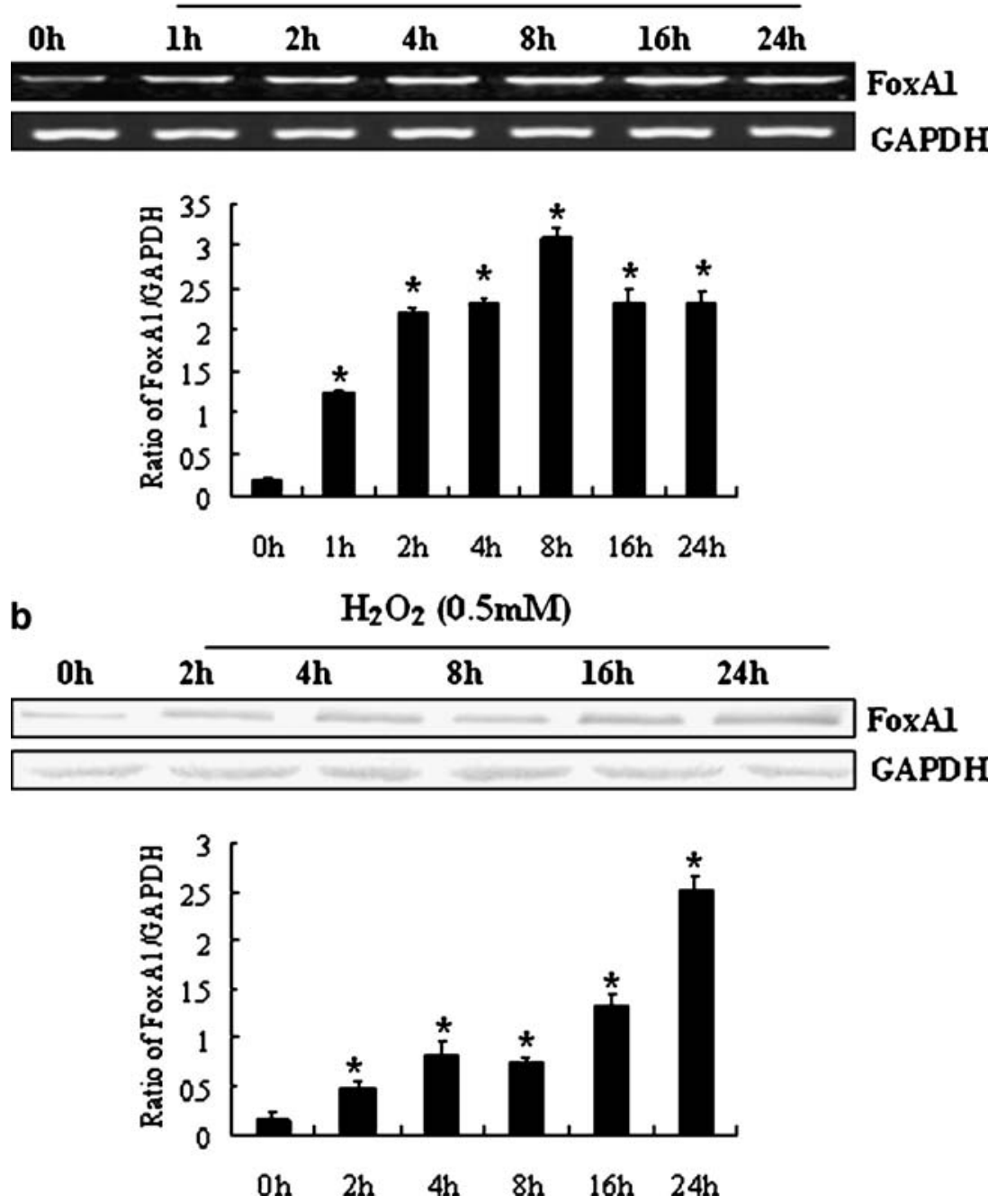

Fig. 4. Expression of FoxA1 in cultured AT-2 cells stimulated with $\mathrm{H}_{2} \mathrm{O}_{2}$. AT-2 cells were stimulated with $\mathrm{H}_{2} \mathrm{O}_{2}(0.5 \mathrm{mM})$ for the indicated periods of time. a mRNA levels of FoxA1 were determined by RT-PCR. b Protein levels of FoxA1 were determined by Western blot. * Statistically significant versus control group, $P<0.05$.

AT-2 cells. The rate of apoptosis was also demonstrated to be increased in AT-2 cells treated with $\mathrm{H}_{2} \mathrm{O}_{2}$ $(0.5 \mathrm{mM})$, a main mediator of OA-induced ALI [1012]. These results demonstrate that AT-2 cells apoptosis occurs during OA-induced ALI.

It is well accepted that FoxA1 plays a critical role in the development and function of the lung [22, 36-38], but to our knowledge this is the first investigation of the role of FoxA1 in ALI. Here, we have demonstrated that FoxA1 mRNA and protein levels are upregulated in rat lung tissue following treatment with OA, suggesting a potential role for FoxA1 in OA-induced ALI. In the adult lung, FoxA1 is expressed in epithelial cells of conducting airways and in AT-2 cells [19]. In addition to being targeted by pathogens, inflammatory cells, and mediators, epithelial cells are also actively involved in the regulation of the inflammatory response [39, 40]. Therefore, we treated AT-2 cells with $\mathrm{H}_{2} \mathrm{O}_{2}(0.5 \mathrm{mM})$ to simulate the acute pulmonary epithelial cell injury observed in vivo. Using this in vitro model of ALI, we 


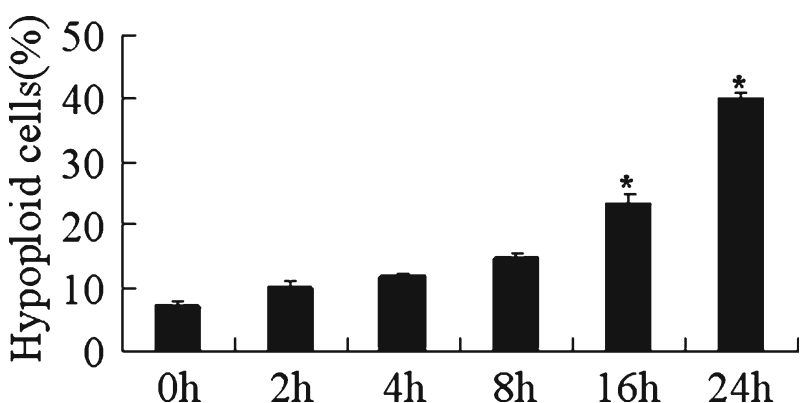

Fig. 5. Apoptosis of AT-2 cells induced by $\mathrm{H}_{2} \mathrm{O}_{2}$. Following treatment of cells with $\mathrm{H}_{2} \mathrm{O}_{2}(0.5 \mathrm{mM})$ for the indicated durations, the rate of apoptosis was measured by flow cytometry. The results were expressed as mean $\pm \mathrm{SD}$ of three experiments in duplicate. *Statistically significant versus the control group, $P<0.05$.

found that expression levels of FoxA1 mRNA and protein was also significantly increased. In addition, we observed a similar FoxA1 expression pattern in both ALI model of rat and cell injury model of AT-2 cells, with maximal expression occurring at $8 \mathrm{~h}$ (mRNA) and $16 \mathrm{~h}$ (protein). Taken together, these data suggest that FoxA1 may play an important role in ALI.

Given that a significant increase in FoxA1 expression and a significant increase in apoptosis was observed in both the in vivo and in vitro model of ALI, we hypothesized that FoxA1 might play an important role in apoptosis of AT-2 cells. To further investigate this, we overexpressed FoxA1 using expression constructs and inhibited FoxA1 expression using antisense oligonucleotides. The results demonstrated that the apoptosis rate of AT-2 cells was increased following FoxA1 overexpression. In contrast, inhibition of FoxA1 resulted in decreased apoptosis $24 \mathrm{~h}$ after $\mathrm{H}_{2} \mathrm{O}_{2}$ treatment. These results suggest that FoxA1 promotes apoptosis of AT-2 cells in ALI. However, $\mathrm{H}_{2} \mathrm{O}_{2}$-induced apoptosis in AT-2 cells was not completely abolished by the transfection of FoxA1 antisense oligonucleotides (Fig. 6a and b). This may be due to incomplete knockdown of FoxA1 using the antisense approach, or alternatively mechanisms of $\mathrm{H}_{2} \mathrm{O}_{2}$-mediated apoptosis may involve activation of further pro-apoptotic genes.

The regulation of pulmonary epithelial cell apoptosis is under investigation in several studies. In patients with ALI, up-regulation of p53 and WAF1 (cyclindependent kinase inhibitor p21) in pulmonary epithelial cells has been demonstrated. p53 and WAF1 are nuclear proteins that are important in cell cycle regulation and homeostasis. Upregulation of these proteins in response to DNA damage either inhibits cell division or facilitates apoptosis. Bardales et al. [39] reported that alveolar pneumocytes isolated from humans with ALI demonstrate upregulation of the pro-apoptotic protein, Bax [39]. In addition, several lines of evidence implicate Fas
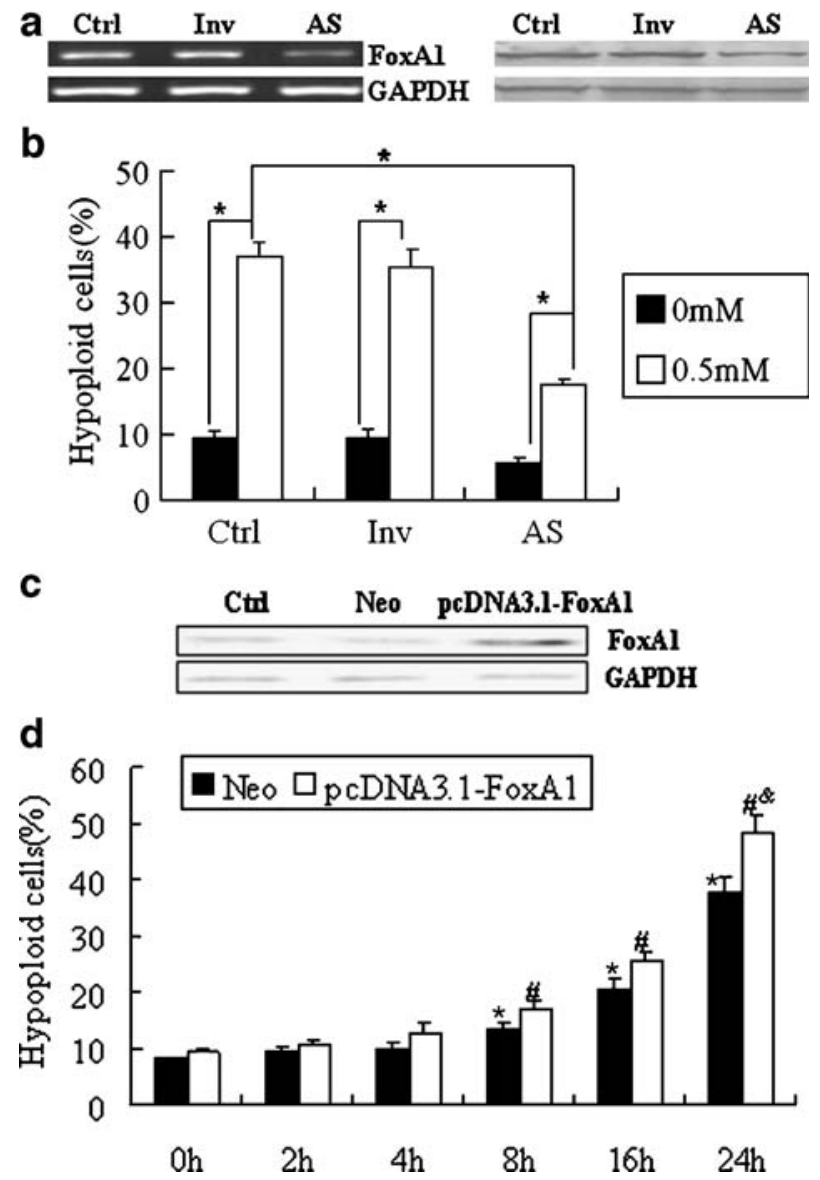

Fig. 6. Effect of FoxA1 deficiency or overexpression on AT-2 cells apoptosis induced by $\mathrm{H}_{2} \mathrm{O}_{2}$. a AT-2 cells were transiently transfected with FoxA1 morpholino antisense oligonucleotides. Expression of FoxA1 was assessed by RT-PCR and Western blotting in order to identify basal FoxA1 inhibition. b Effect of FoxA1 deficiency on the apoptosis of AT-2 cells induced by $\mathrm{H}_{2} \mathrm{O}_{2}(0.5 \mathrm{mM}$ for $24 \mathrm{~h})$. Ctrl: AT-2 cells were treated with lipofectamine only; Inv: AT-2 cells were transiently transfected with random FoxA1 oligonucleotides; $A S$ : AT-2 cells were transiently transfected with FoxA1 morpholino antisense oligonucleotides. ${ }^{*} P<0.05$. c AT- 2 cells were transfected with pcDNA3.1FoxA1 and the expression levels of FoxA1 were assessed by Western blot. d Effect of FoxA1 overexpression on the apoptosis of AT- 2 cells induced by $\mathrm{H}_{2} \mathrm{O}_{2}(0.5 \mathrm{mM})$. Ctrl: AT-2 cells were treated with lipofectamine only; Neo: vector control group; pcDNA3.1-FoxA1: FoxA1 overexpression group. The results were expressed as mean $\pm \mathrm{SD}$ of three experiments in duplicate. Cells were treated with $\mathrm{H}_{2} \mathrm{O}_{2}(0.5 \mathrm{mM})$ for indicated durations. *Statistically significant versus the Neo group at $0 \mathrm{~h}, P<0.05$.

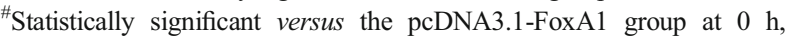
$P<0.05$. ${ }^{\&}$ Statistically significant versus the Neo group at $24 \mathrm{~h}, P<0.05$. 
and Fas ligand in alveolar epithelial cell apoptosis during ALI [13, 14, 34, 41-43]. However, this is the first investigation into the role of FoxA1 in apoptosis during ALI. We hypothesize that the transcription factor FoxA1 promotes apoptosis of AT-2 cells during ALI through regulation of apoptosis-related genes. Further investigation is needed in order to elucidate the exact mechanism by which FoxA1 mediated apoptosis during ALI.

In summary, our study demonstrates that FoxA1 is induced in rat lung tissue during ALI and in $\mathrm{H}_{2} \mathrm{O}_{2}$ treated human pulmonary epithelial cells. FoxA1 potentially acts as a pro-apoptotic transcription factor and may play an important role in type II pulmonary epithelial apoptosis in ALI. Further clarification of the exact role of FoxA1 in pulmonary epithelial cell apoptosis may have clinical significance for the pathogenesis and treatment of ALI.

\section{ACKNOWLEDGMENTS}

This work was supported by the National Nature Science Foundation of China (grant no. 30330280), the National Nature Science Foundation of Hunan, China (grant no. 08JJ3030) and the Science Foundation Health Department of Hunan, China (grant no. 2007B090).

\section{REFERENCES}

1. Goss, C. H., R. G. Brower, L. D. Hudson, and G. D. Rubenfeld. 2003. Incidence of acute lung injury in the United States. Crit. Care Med. 31:1607-1611. doi:10.1097/01.CCM.0000063475. 65751.1D.

2. Mendez, J. L., and R. D. Hubmayr. 2005. New insights into the pathology of acute respiratory failure. Curr. Opin. Crit. Care. 11:29-36. doi:10.1097/00075198-200502000-00005.

3. Rubenfeld, G. D., E. Caldwell, E. Peabody, J. Weaver, D. P. Martin, M. Neff, et al. 2005. Incidence and outcomes of acute lung injury. $N$. Engl. J. Med. 353:1685-1693. doi:10.1056/NEJMoa050333.

4. Ware, L. B., and M. A. Matthay. 2000. The acute respiratory distress syndrome. N. Engl. J. Med. 342:1334-1349. doi:10.1056/ NEJM200005043421806.

5. Crimi, E., and A. S. Slutsky. 2004. Inflammation and the acute respiratory distress syndrome. Best Pract. Res. Clin. Anaesthesiol. 18:477-492. doi:10.1016/j.bpa.2003.12.007.

6. Ventilation with lower tidal volumes as compared with traditional tidal volumes for acute lung injury and the acute respiratory distress syndrome. The Acute Respiratory Distress Syndrome Network. N. Engl. J. Med. 342:1301-1308. doi:10.1056/NEJM 200005043421801

7. Matthay, M. A., G. A. Zimmerman, C. Esmon, J. Bhattacharya, B. Coller, C. M. Doerschuk, et al. 2003. Future research directions in acute lung injury: summary of a National Heart, Lung, and Blood
Institute working group. Am. J. Respir. Crit. Care Med. 167:10271035. doi:10.1164/rccm.200208-966WS.

8. Mehta, D., J. Bhattacharya, M. A. Matthay, and A. B. Malik. 2004. Integrated control of lung fluid balance. Am. J. Physiol. Lung Cell. Mol. Physiol. 287:L1081-L1090. doi:10.1152/ajplung.00268. 2004.

9. Slutsky, A. S., and L. D. Hudson. 2006. PEEP or no PEEP-lung recruitment may be the solution. N. Engl. J. Med. 354:1839-1841. doi:10.1056/NEJMe068045.

10. Tampo, Y., M. Tsukamoto, and M. Yonaha. 1999. Superoxide production from paraquat evoked by exogenous NADPH in pulmonary endothelial cells. Free Radic. Biol. Med. 27:588-595. doi:10.1016/S0891-5849(99)00110-0.

11. Zhang, H., A. S. Slutsky, and J. L. Vincent. 2000. Oxygen free radicals in ARDS, septic shock and organ dysfunction. Intensive Care Med. 26:474-476. doi:10.1007/s001340051185.

12. Yang, C., H. Moriuchi, J. Takase, Y. Ishitsuka, M. Irikura, and T. Irie. 2003. Oxidative stress in early stage of acute lung injury induced with oleic acid in guinea pigs. Biol. Pharm. Bull. 26:424 428. doi:10.1248/bpb.26.424.

13. Albertine, K. H., M. F. Soulier, Z. Wang, A. Ishizaka, S. Hashimoto, G. A. Zimmerman, et al. 2002. Fas and fas ligand are up-regulated in pulmonary edema fluid and lung tissue of patients with acute lung injury and the acute respiratory distress syndrome. Am. J. Pathol. 161:1783-1796.

14. Kitamura, Y., S. Hashimoto, N. Mizuta, A. Kobayashi, K. Kooguchi, I. Fujiwara, et al. 2001. Fas/FasL-dependent apoptosis of alveolar cells after lipopolysaccharide-induced lung injury in mice. Am. J. Respir. Crit. Care Med. 163:762-769.

15. Monaghan, A. P., K. H. Kaestner, E. Grau, and G. Schutz. 1993. Postimplantation expression patterns indicate a role for the mouse forkhead/HNF-3 alpha, beta and gamma genes in determination of the definitive endoderm, chordamesoderm and neuroectoderm. Development 119:567-578.

16. Ang, S. L., A. Wierda, D. Wong, K. A. Stevens, S. Cascio, J. Rossant, et al. 1993. The formation and maintenance of the definitive endoderm lineage in the mouse: involvement of HNF3/ forkhead proteins. Development 119:1301-1315.

17. Sasaki, H., and B. L. Hogan. 1993. Differential expression of multiple fork head related genes during gastrulation and axial pattern formation in the mouse embryo. Development 118:47-59.

18. Ruiz i Altaba, A., C. Cox, T. M. Jessell, and A. Klar. 1993. Ectopic neural expression of a floor plate marker in frog embryos injected with the midline transcription factor Pintallavis. Proc. Natl. Acad. Sci. U. S. A. 90:8268-8272. doi:10.1073/pnas.90.17.8268.

19. Besnard, V., S. E. Wert, W. M. Hull, and J. A. Whitsett. 2004. Immunohistochemical localization of Foxa1 and Foxa2 in mouse embryos and adult tissues. Gene Expr. Patterns 5:193-208. doi:10.1016/j.modgep.2004.08.006.

20. Kaestner, K. H., H. Hiemisch, B. Luckow, and G. Schutz. 1994. The HNF-3 gene family of transcription factors in mice: gene structure, cDNA sequence, and mRNA distribution. Genomics 20:377-385. doi:10.1006/geno.1994.1191.

21. Lai, E., V. R. Prezioso, E. Smith, O. Litvin, R. H. Costa, and J. E. Darnell Jr. 1990. HNF-3A, a hepatocyte-enriched transcription factor of novel structure is regulated transcriptionally. Genes Dev. 4:1427-1436. doi:10.1101/gad.4.8.1427.

22. Besnard, V., S. E. Wert, K. H. Kaestner, and J. A. Whitsett. 2005. Stage-specific regulation of respiratory epithelial cell differentiation by Foxa1. Am. J. Physiol. Lung Cell. Mol. Physiol. 289:L750L759. doi:10.1152/ajplung.00151.2005.

23. Vazquez de Lara, L., C. Becerril, M. Montano, C. Ramos, V. Maldonado, J. Melendez, et al. 2000. Surfactant components modulate fibroblast apoptosis and type I collagen and collagenase-1 expression. Am. J. Physiol. Lung Cell. Mol. Physiol. 279: L950-L957. 
24. White, M. K., V. Baireddy, and D. S. Strayer. 2001. Natural protection from apoptosis by surfactant protein A in type II pneumocytes. Exp. Cell. Res. 263:183-192. doi:10.1006/ excr.2000.5120.

25. Minoo, P., L. Hu, Y. Xing, N. L. Zhu, H. Chen, M. Li, et al. 2007. Physical and functional interactions between homeodomain NKX2.1 and winged helix/forkhead FOXA1 in lung epithelial cells. Mol. Cell. Biol. 27:2155-65. doi:10.1128/MCB.01133-06.

26. Nishina, K., K. Mikawa, Y. Takao, N. Maekawa, M. Shiga, and H. Obara. 1997. ONO-5046, an elastase inhibitor, attenuates endotoxin-induced acute lung injury in rabbits. Anesth. Analg. 84:10971103. doi:10.1097/00000539-199705000-00026.

27. Schittny, J. C., V. Djonov, A. Fine, and P. H. Burri. 1998. Programmed cell death contributes to postnatal lung development. Am. J. Respir. Cell. Mol. Biol. 18:786-793.

28. Mulier, B., I. Rahman, T. Watchorn, K. Donaldson, W. MacNee, and P. K. Jeffery. 1998. Hydrogen peroxide-induced epithelial injury: the protective role of intracellular nonprotein thiols (NPSH). Eur. Respir. J. 11:384-91. doi:10.1183/09031936.98.11020384.

29. Roberts, J. R., G. D. Perkins, T. Fujisawa, K. A. Pettigrew, F. Gao, A. Ahmed, et al. 2007. Vascular endothelial growth factor promotes physical wound repair and is anti-apoptotic in primary distal lung epithelial and A549 cells. Crit. Care Med. 35:21642170. doi:10.1097/01.CCM.0000281451.73202.F6.

30. Lockshin, R. A. 2005. Programmed cell death: history and future of a concept. J. Soc. Biol. 199:169-173. doi:10.1051/jbio:2005017.

31. Iuchi, T., M. Akaike, T. Mitsui, Y. Ohshima, Y. Shintani, H. Azuma, et al. 2003. Glucocorticoid excess induces superoxide production in vascular endothelial cells and elicits vascular endothelial dysfunction. Circ. Res. 92:81-87. doi:10.1161/01. RES.0000050588.35034.3C.

32. Cox, G., J. Crossley, and Z. Xing. 1995. Macrophage engulfment of apoptotic neutrophils contributes to the resolution of acute pulmonary inflammation in vivo. Am. J. Respir. Cell. Mol. Biol. 12:232-237.

33. Haslett, C., J. S. Savill, M. K. Whyte, M. Stern, I. Dransfield, and L. C. Meagher. 1994. Granulocyte apoptosis and the control of inflammation. Philos. Trans. R. Soc. Lond. B Biol. Sci. 345:327333. doi:10.1098/rstb.1994.0113.

34. Matute-Bello, G., W. C. Liles, K. P. Steinberg, P. A. Kiener, S. Mongovin, E. Y. Chi, et al. 1999. Soluble Fas ligand induces epithelial cell apoptosis in humans with acute lung injury (ARDS). J. Immunol. 163:2217-2225.
35. Hashimoto, S., A. Kobayashi, K. Kooguchi, Y. Kitamura, H. Onodera, and H. Nakajima. 2000. Upregulation of two death pathways of perforin/granzyme and FasL/Fas in septic acute respiratory distress syndrome. Am. J. Respir. Crit. Care Med. 161:237-243.

36. Wan, H., S. Dingle, Y. Xu, V. Besnard, K. H. Kaestner, S. L. Ang, et al. 2005. Compensatory roles of Foxa1 and Foxa2 during lung morphogenesis. J. Biol. Chem. 280:13809-13816. doi:10.1074/jbc. M414122200.

37. Whitsett, J. A., and Y. Matsuzaki. 2006. Transcriptional regulation of perinatal lung maturation. Pediatr. Clin. North Am. 53:873-887. viii. doi:10.1016/j.pcl.2006.08.009.

38. Park, K. S., J. M. Wells, A. M. Zorn, S. E. Wert, V. E. Laubach, L. G. Fernandez, et al. 2006. Transdifferentiation of ciliated cells during repair of the respiratory epithelium. Am. J. Respir. Cell. Mol. Biol. 34:151-157 doi:10.1165/rcmb.2005-0332OC.

39. Bardales, R. H., S. S. Xie, R. F. Schaefer, and S. M. Hsu. 1996. Apoptosis is a major pathway responsible for the resolution of type II pneumocytes in acute lung injury. Am. J. Pathol. 149: $845-852$.

40. Wang, H. C., C. T. Shun, S. M. Hsu, S. H. Kuo, K. T. Luh, and P. C. Yang. 2002. Fas/Fas ligand pathway is involved in the resolution of type II pneumocyte hyperplasia after acute lung injury: evidence from a rat model. Crit. Care Med. 30:1528-34. doi:10.1097/00003246-200207000-00022.

41. Tewari, M., L. T. Quan, K. O'Rourke, S. Desnoyers, Z. Zeng, D. R. Beidler, et al. 1995. Yama/CPP32 beta, a mammalian homolog of CED-3, is a CrmA-inhibitable protease that cleaves the death substrate poly(ADP-ribose) polymerase. Cell 81:801-809. doi:10.1016/0092-8674(95)90541-3.

42. Matute-Bello, G., W. C. Liles, C. W. Frevert, M. Nakamura, K. Ballman, C. Vathanaprida, et al. 2001. Recombinant human Fas ligand induces alveolar epithelial cell apoptosis and lung injury in rabbits. Am. J. Physiol. Lung Cell. Mol. Physiol. 281:L328-L335.

43. Matute-Bello, G., R. K. Winn, M. Jonas, E. Y. Chi, T. R. Martin, and W. C. Liles. 2001. Fas (CD95) induces alveolar epithelial cell apoptosis in vivo: implications for acute pulmonary inflammation. Am. J. Pathol. 158:153-161.

44. Dobbs, L. G., R. Gonzalez, and M. C. Williams. 1986. An improved method for isolating type II cells in high yield and purity. Am. Rev. Respir. Dis. 134:141-145.

45. Dobbs, L. G. 1990. Isolation and culture of alveolar type II cells. Am. J. Physiol. 258:L134-L147. 